\title{
A Novel Delta Modulator and Modified Ramp Type Current Controller-Two Viable Scheme for Current Controlled Voltage Source Inverter
}

\author{
B.Chitti Babu \\ Dept. of Electrical Engineering \\ National Institute of Technology \\ Rourkela-769008, INDIA
}

\author{
B.Vasantha Reddy \\ Dept. of Electrical Engineering \\ National Institute of Technology \\ Rourkela-769008, INDIA
}

\author{
K.B.Mohanty \\ Dept. of Electrical Engineering \\ National Institute of Technology \\ Rourkela-769008, INDIA
}

\begin{abstract}
Three-phase pwm voltage source inverters are widely employed in high performance ac drive system, active filters and uninterrupted power supply (UPS) etc.For these applications, the converter should provides good dynamic response. However the performance of the converter system largely depends on the accuracy of the applied current control strategy. The current controllers can be classified as linear and non-linear current controllers. Linear current controller includes PI (synchronous \& stationary reference frame) controller, state feed back controller and predictive current controller. Nonlinear current controller includes ramp type, hysteresis controller and delta modulator etc.This paper presents a novel delta modulator and modified ramp type current controller for current controlled voltage source inverter. Delta modulator provides constant switching frequency during load parameter changes and it gives good dynamic response. Modified ramp type current controller provides lower value of THD and it reduces the lower order harmonic content in the three-phase load current. The comparative study between these two current controllers is verified through MATLAB computer simulation environment and THD level of three-phase load currents have been calculated for different value of load parameters.
\end{abstract}

\section{Keywords}

Hysteresis current controller, delta modulator, voltage source inverter (VSI), total harmonic distortion (THD), pulse width modulation (PWM), switching frequency.

\section{INTRODUCTION}

Three-phase pwm voltage source inverters are widely employed in high performance ac drive system, active filters and uninterrupted power supply (UPS) etc where the dynamics are important concern. For these applications, the power electronics converter has an internal current control loop and its performance largely depends on the quality of the applied current control strategy. Various current controllers were proposed in the literature for voltage source inverter, these are linear and nonlinear current controllers [1]-[5]. Linear controller includes proportional integral controller, state feed back controller and predictive current controller. Nonlinear controller includes Hysteresis control, ramp type control and delta modulator. Linear current controller requires the complete knowledge of load parameters and it needs more calculation. But nonlinear controller does not need the load information and it provides good dynamic response to the system.

The main objective of using current controller is to force the load current to follow the reference current trajectory. By comparing the reference command and measured value of instantaneous values of phase currents, the current controller generates the switching pattern for the power converter which reduces the current error. Hence the current controller performs two functions: Error compensation and modulation for switching states. Basically current controller should have the following key features.1) extremely good dynamics 2) Instantaneous control of load current with good accuracy 3) over current protection 4) over load rejection 5) Compensation during load parameter changes 6) compensation during parameter sensitivity 7) maintaining dc link and ac link voltages constant etc [6].

Most of the voltage source inverter applications nonlinear feed back hysteresis current control technique has been universally employed because of its simplicity in implementation, inherently reducing the current error and very fast response. But the controller does not give guaranty for parameter sensitivity and the switching frequency variation over the fundamental period [7].The ramp-comparator controller compares the error current signal to a carrier waveform to generate the inverter firing pulses [3]-[7]. The main advantage of the ramp comparison technique is that the inverter switching is usually limited to the frequency of the career waveform, and the produced harmonics are defined at a fixed frequency. However, the system response is purely depends on load parameters and it is affected by the stability requirements of the feedback loop, Thus, inherent phase and amplitude errors arise during steadystate condition.

In this paper, novel delta modulator which has zero hysteresis and modified ramp type current controller for voltage source inverter are focused. Modified ramp type controller reduces the phase and amplitude error due to load current variations and it gives minimum value of THD for load current. Delta modulator provides constant switching frequency over the fundamental period and it gives fast control action. In the uniformly sampled form of the delta modulated current regulator, the hysteresis band may be zero because the sample rate limits the switching 
frequency of the delta modulator [8]. Delta Modulation requires very simple circuit implementation and it provides smooth transition between the PWM and single pulse modes without need of additional circuit complexity. In delta modulation a triangular wave is allowed to oscillate within the defined window above and below reference sine wave. This mode of operation gives a discretization of inverter output voltage, which is opposite to the capability of continuous variation of output voltages particularly in the case of ramp type controller. The comparative study between these two current controllers is verified through MATLAB computer simulation environment and THD level of three-phase load currents have been calculated for different value of load parameters.

\section{Basic Concept of Current Control \& Its Requirements}

The operation of current-controlled voltage source inverter can be studied by considering the circuit shown in fig (1). With advances in modern power semiconductor technology fast switching devices such as IGBT's and IGCT's are widely used as switches in inverter circuits. In this circuit three phase R-L load is connected to the three phase PWM inverter. The load currents are compared with the reference currents, and error signals are passes through current controller to generate the firing pulses, which are operated to produce output voltage in manner to reduce the current error. The inverter conduction state is represented by logics NA, NB, NC. Logic " 1 "means $T_{1}$ is conducting logic " 0 " means T4 conducting. The conduction modes of the inverter are given in Table I. Fig (2) shows the voltage vectors corresponding to the six active states. Each vector has an amplitude of $2 \mathrm{~V}_{\mathrm{DC}} / 3$. The magnitude of the voltage vectors $\mathrm{u}_{0}$ and $\mathrm{u}_{7}$ corresponding to the freewheeling states, which equal to zero. The magnitude of voltage $\mathrm{u}_{0}$ is zero when the upper switches T1, T3, T5 are OFF and lower switches T4, T6, T2 are ON. Similarly, the magnitude of the voltage vector $\mathbf{u}_{7}$ is zero when the upper switchesT1, T3, T5 are ON and lower switches T4, T6, T2 are OFF. It means no voltage is applied to the load.

Actually the characteristics required from the current controller are fast current control with good accuracy during transient conditions and a low harmonic content during steady state conditions. Modulation process controls the switching sequence according to the reference commend and it produces the output voltage waveform as close as possible to the sinusoidal wave. Hence, modulation generates higher order voltage harmonics, located around the switching frequency. It also produce the current ripple due to instantaneous deviation of the current from the reference commend and its amplitude depends on the modulation switching time instant (i.e. switching frequency) and its load parameters (R, L and E).During load variations, the frequency of the modulation must vary in order to keep the current ripple constant, switching loss occurs in the switch impose the limitation on the switching frequency. Hence, during variation in the load and parameter sensitivity, the inverter switch should maintain the constant switching frequency. But these two requirements are contradictory each other. When phase voltages can be controlled independently, phase currents are determines by their own phase voltages and other phase voltages and it leads to phase interference effect, it should also be considered while designing a current controller [9]. For successful operation of current controller, DC link voltage should be enough to force the load current to follow the reference command. If the ac output voltage increases to a six step square wave operation, DC link voltage is not capable to force the command value. Therefore the converter should have sufficient DC link voltage to force the line current for the entire load value.

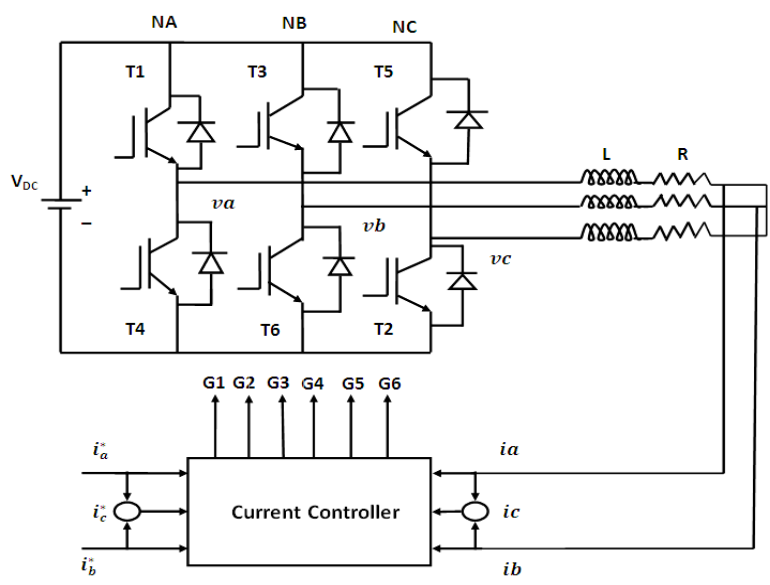

Fig.1. Basic circuit of current controlled voltage source inverter

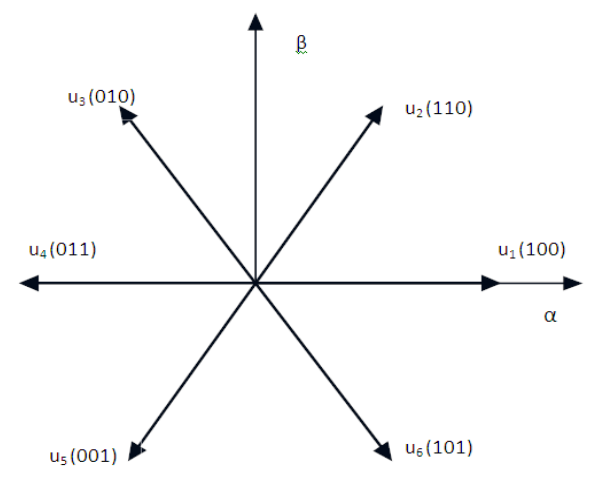

Fig.2. Switching states of voltage source inverter

Table: 1-mode of operation of voltage source inverter

\begin{tabular}{|c|cc|cc|cc|c|c|}
\hline State & $\mathbf{T}_{\mathbf{1}}$ & $\mathbf{T}_{\mathbf{4}}$ & $\mathbf{T}_{\mathbf{3}}$ & $\mathbf{T}_{\mathbf{6}}$ & $\mathbf{T}_{\mathbf{5}}$ & $\mathbf{T}_{\mathbf{2}}$ & Operation mode & Voltage vector \\
\hline 0 & 0 & 1 & 0 & 1 & 0 & 1 & freewheeling & $\mathrm{u}_{0}$ \\
\hline 1 & 1 & 0 & 0 & 1 & 0 & 1 & active & $\mathrm{u}_{1}$ \\
\hline 2 & 0 & 1 & 1 & 0 & 0 & 1 & active & $\mathrm{u}_{2}$ \\
\hline 3 & 1 & 0 & 1 & 0 & 0 & 1 & active & $\mathrm{u}_{3}$ \\
\hline 4 & 0 & 1 & 0 & 1 & 1 & 0 & active & $\mathrm{u}_{4}$ \\
\hline 5 & 1 & 0 & 0 & 1 & 1 & 0 & active & $\mathrm{u}_{5}$ \\
\hline 6 & 0 & 1 & 1 & 0 & 1 & 0 & active & $\mathrm{u}_{6}$ \\
\hline 7 & 1 & 0 & 1 & 0 & 1 & 0 & freewheeling & $\mathrm{u}_{7}$ \\
\hline
\end{tabular}




\section{A Novel Delta Modulator}

The basic circuit for sampled form of delta modulated current controller is shown in fig.3(a).In delta modulation scheme for inverters, the input signal to controller is sine wave and output is the modulated waveform. The feedback path consists of an integrator filter and the forward path consists of a Hysteresis quantizer. The input signal and the signal derived from the modulator output by low pass filtering of the integrator are compared to produce error signal. The quantizer determines this error signal to produce the modulated wave in such manner that error is minimized and kept between certain levels. The integrator shown in fig.3(c), when used in the feedback path of the modulator output low pass filtering having fixed cut off frequency determined by the following transfer function:

$\frac{e_{0}(s)}{e_{i}(s)}=\frac{K}{\tau s+1}$

\section{(1)}

where $K$ is the gain of the filter $=-\mathrm{R}_{2} / \mathrm{R}_{1}$ and $\tau$ is the time constant of the filter $=\mathrm{R}_{2} \mathrm{C}$.
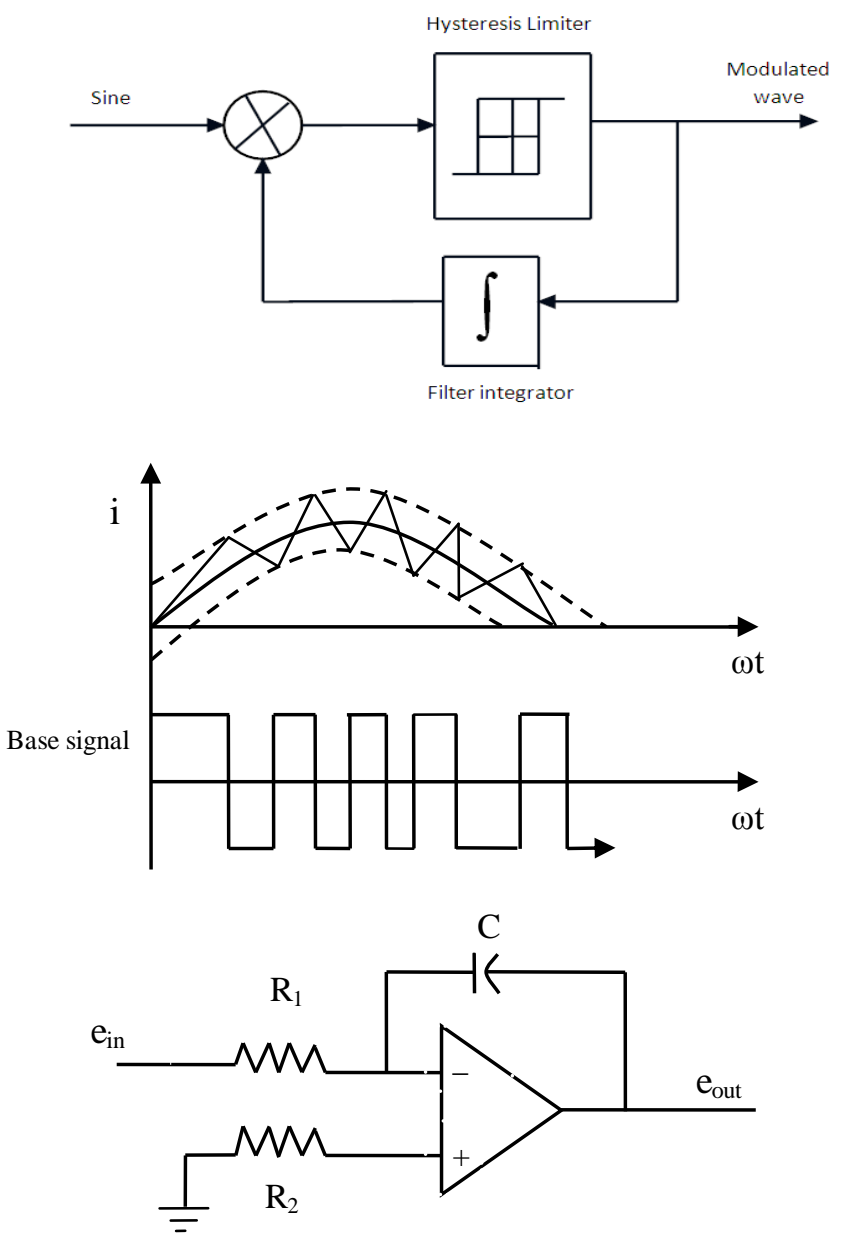

Fig.3. (a) block diagram of simple delta modulator (b) control action (c) Integrated filter
Since the above filter has a fixed cutoff frequency $f_{c}$, the harmonic contents in the output currents of the modulator can be changed by changing the time constant of the integrator or cutoff frequency. The delta modulation offers an opportunity of on-line harmonic minimization of pulse width modulated inverter without conventional optimization processes, like selective harmonic elimination or harmonic weighting techniques. At very high frequency operation of double integrator modulators experiences instability. These limitations restrict the wide application of double integrator delta modulator in inverter operations.

\section{Modified Ramp Type Current Controller}

A ramp comparator controller is shown in fig. 4. The actual load currents are measured and compared with reference current waveforms. The generated error signals are compared with triangular waveforms of fixed frequency (to maintain constant switching frequency of voltage source inverter at frequency of triangular waveform). If the current error is positive and larger than the triangular wave, the inverter switches are activated to apply $+\mathrm{VB}$ to load. However if the current error is smaller then the triangular wave, inverter switches are activated to apply -VB to load. In order to avoid multiple crossings of error signal with triangular wave Hysteresis band is added. The feature of ramp comparator current control is to maintain constant switching frequency with lower harmonic content. However this controller has some disadvantages, as the output current has amplitude and phase errors. This result in transmission delay in the system, a zero voltage is applied to load. This means that load is disconnected several times over the fundamental period. To avoid phase and amplitude errors phase shifters are included. The current error signals are compared with $120^{\circ}$ phase-shifted triangular waveforms having fixed frequency and amplitude. It is to be noted that there is no interaction between the phases. As a result, the zero voltage vectors will be eliminated for balanced operation. This does not lead to the possibility of creating the positive and negative sequence currents due to controller alone. The zero voltage vectors eliminate the necessity of neutral connections for some applications, in such cases no harmonic neutral current flow in the load.

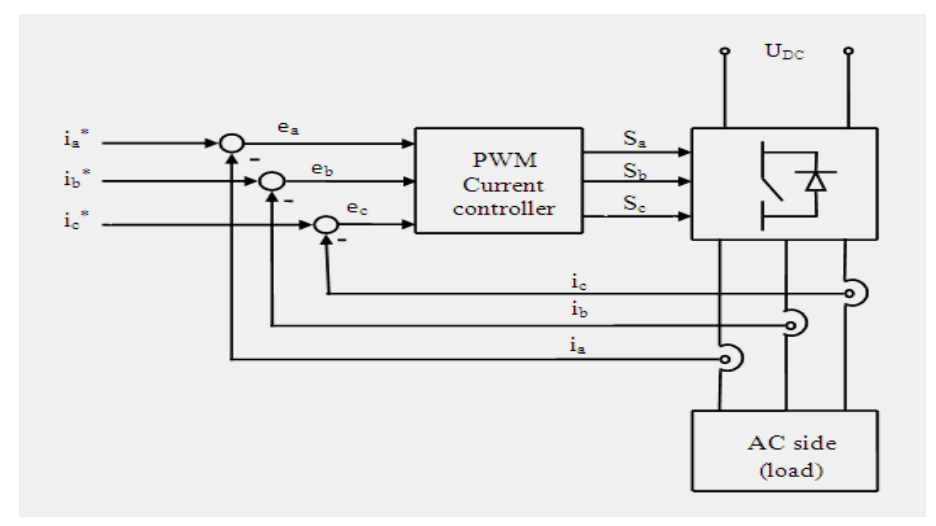

Fig. 4. Voltage source inverter with ramp type current controller 


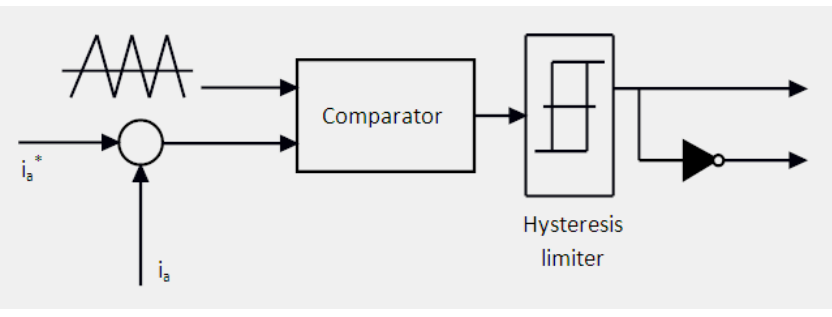

Fig.5.Modified ramp type current controller structure

\section{Simulation Results \& Discussion}

The comparative study between delta modulator and modified ramp type current controller have been analyzed in terms of current controller performance, error current minimization, dynamic response and level of THD for load currents through MATLAB simulink environment The values of load and other parameters are given as follows: Resistance: $2 \Omega$; inductance: $5 \mathrm{mH}$; DC link voltage: $350 \mathrm{~V}$; Reference current: $10 \mathrm{~A}$; In order to find the efficient performance, the controller is tested at ideal load conditions. The harmonic spectrum of load current waveform is analyzed using the fast fourier transform (FFT). The analysis of delta modulator current controller was carried out for a three-phase voltage source inverter at same load conditions. Usually three-phase load is neutrally isolated here in order to eliminate the harmonic neutral current. This action can be accomplished by zero voltage vectors in the switching states. Fig. 6 shows the three-phase reference current waveforms under steady state conditions. Fig.7 shows the three-phase load current waveforms after current compensation by delta modulator and we observed that the three-phase current waveforms drawn from the inverter are approximately free from the harmonics.Fig. 8 shows the current error signal produced by the delta modulator and it was almost minimized by it. The corresponding harmonic spectrum of load current waveform shown by the fig. 9 and it holds the level of THD as per IEEE standard (less than $5 \%$ ) which is depicted in the fig. 10 . Usually in delta modulator, the switching frequency of the inverter is decided by the cut-off frequency of the filter and it can be maintained constant according to the values of $\mathrm{R}$ and $\mathrm{C}$. So during load parameter changes the switching frequency is maintained constant by fixed cut-off frequency of the filter. For justifying the above information, this study has been extended for dynamic studies during load variations. Table 3 depicts the variation of load along with magnitude of harmonic content with constant switching frequency of $2 \mathrm{KHz}$. From this, we observed that the delta modulator provides constant switching frequency and less harmonic current content unlike conventional hysteresis controller.

The same load parameter has been considered for modified ramp type current controller. Fig. 11 shows the response of three-phase load current waveform with the action of modified ramp type current controller. Since the inverter switching frequency is limited to that of carrier frequency, it produces less current error when compared to conventional ramp type controller. This current error signal is shown in the Fig.12.The actual load current follows the reference sinusoidal current wave and it fixes the lower harmonic current content at the switching frequency of the inverter switch. The corresponding harmonic spectrum of three-phase load current waveform shown in the fig. 13 and it almost reduces the lower order harmonics. So the load current profile and its harmonic spectra are defined exactly. As stated above, Modulation process controls the switching sequence according to the reference command and it produces the output voltage waveform as close as possible to the sinusoidal wave. Hence, modulation generates higher order voltage harmonics, located around the switching frequency. To examine the dynamic response of such controller, variable load condition has considered and it tabulated in the Table: 3 and it shows that the ramp type current controller provides less THD level of load currents as per IEEE 519-1992 standard. But modulation process generates higher order harmonics around the switching frequency and it produces more current ripple. If the controller wants to provide less current ripple, then it must vary the modulation frequency. But it leads to increase the switching loss of the converter switches. Table: 2 gives the comparative study between delta and modified ramp type current controller for the switching frequency of $2 \mathrm{KHz}$. The current error movements in $\alpha-\beta$ plane produced by both the controllers are shown in the fig. 15 and 17 respectively.

Table: 2 Comparison between delta and modified current controllers

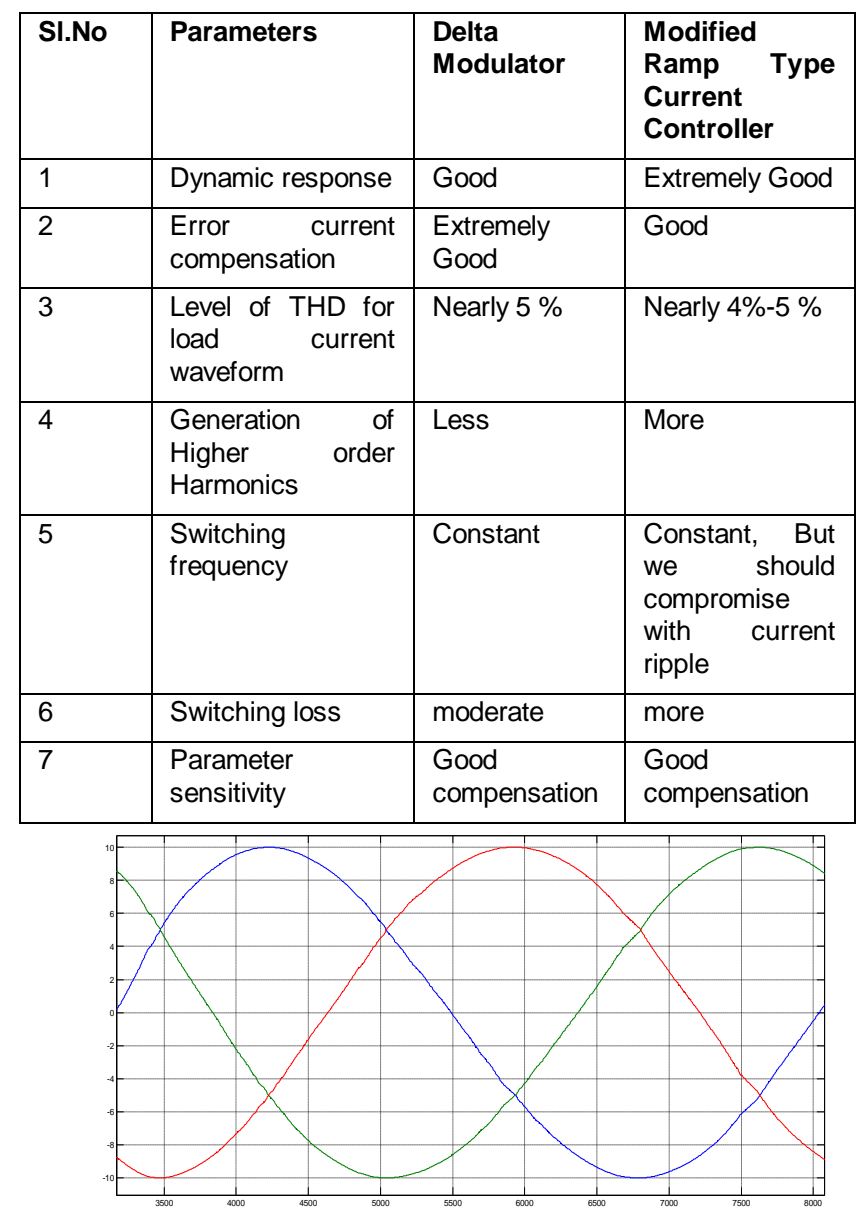

Fig.6 Three-phase reference current waveforms 


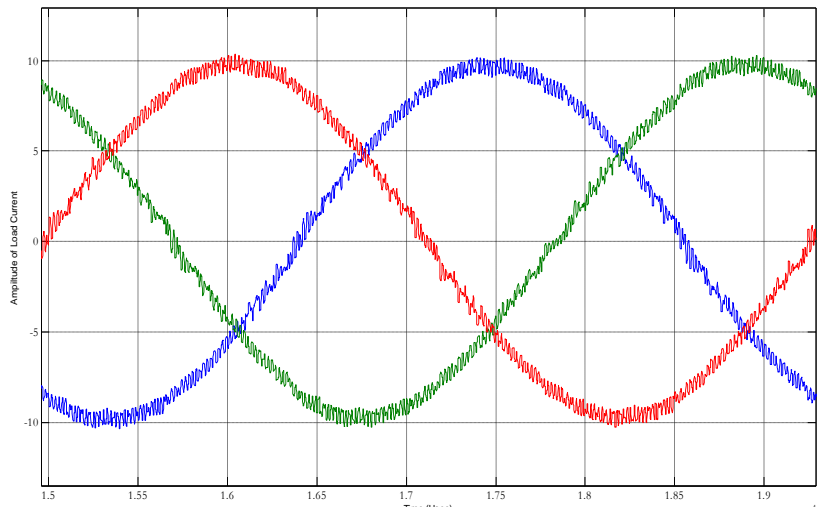

Fig.7 Three-phase load current waveforms with delta modulator

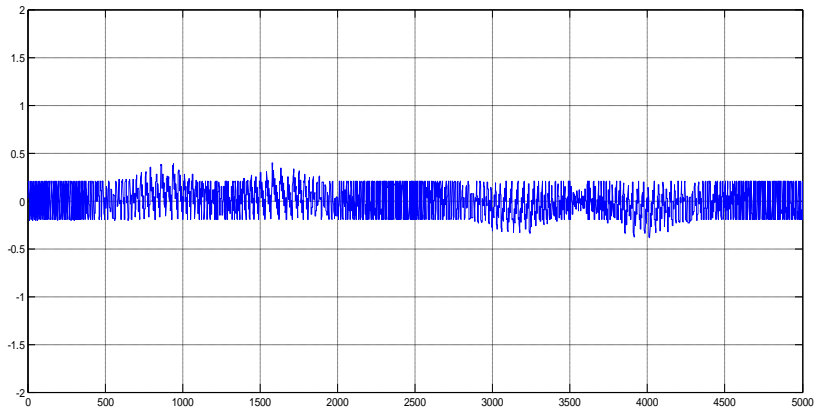

Fig.8.current error signal by delta modulator

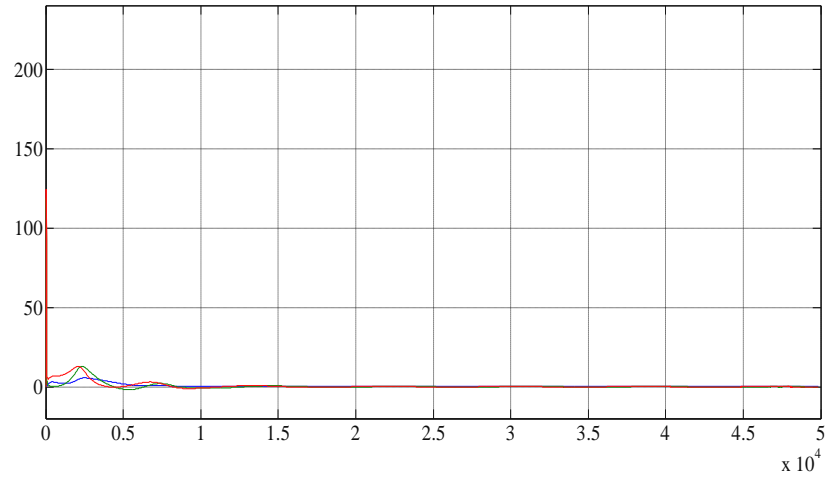

Fig.9.Harmonic spectrum of load current with delta modulator

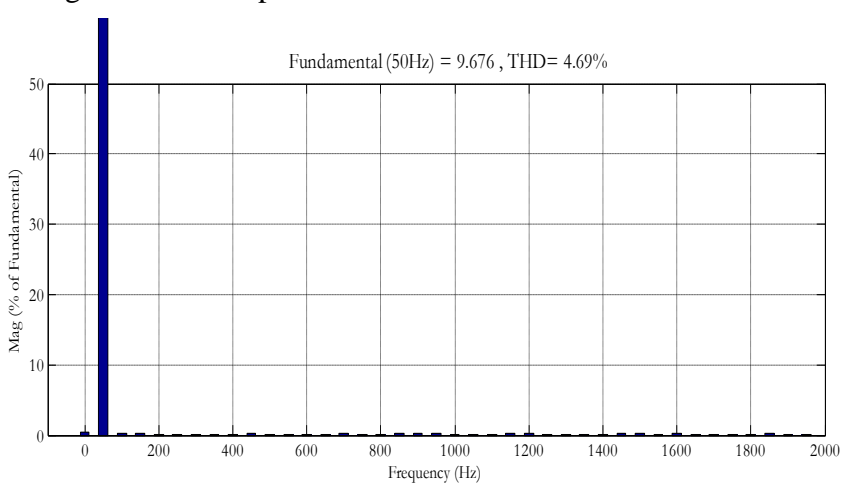

Fig.10.THD level of load current with delta modulator for $\mathrm{R}=3 \mathrm{ohm}$, $\mathrm{L}=5 \mathrm{mH}$

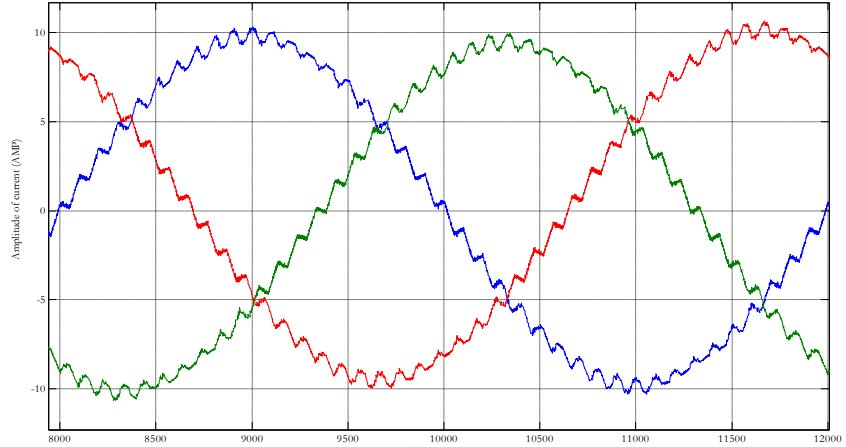

Fig.11 Three-phase load current waveforms with modified ramp type controller

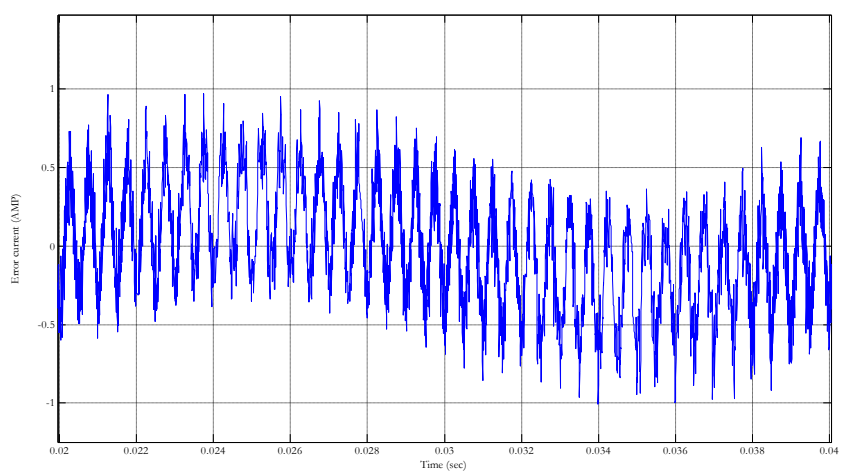

Fig.12.current error signal by modified ramp type controller

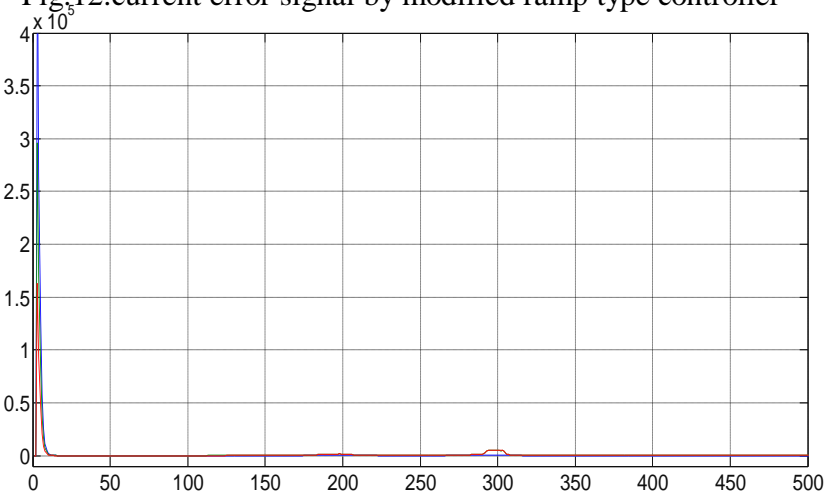

Fig.13.Harmonic spectrum of load current with modified ramp type controller

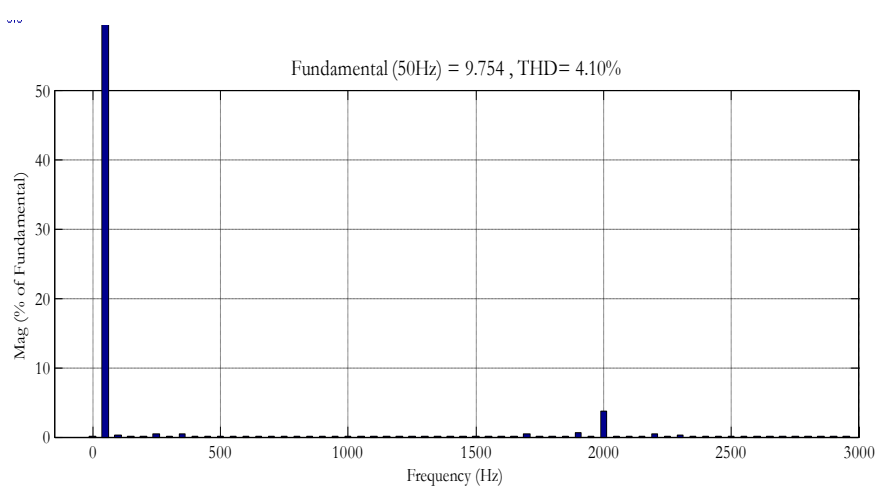

Fig.14.THD level of load current with modified ramp type controller for $\mathrm{R}=3 \mathrm{ohm}, \mathrm{L}=5 \mathrm{mH}$ 


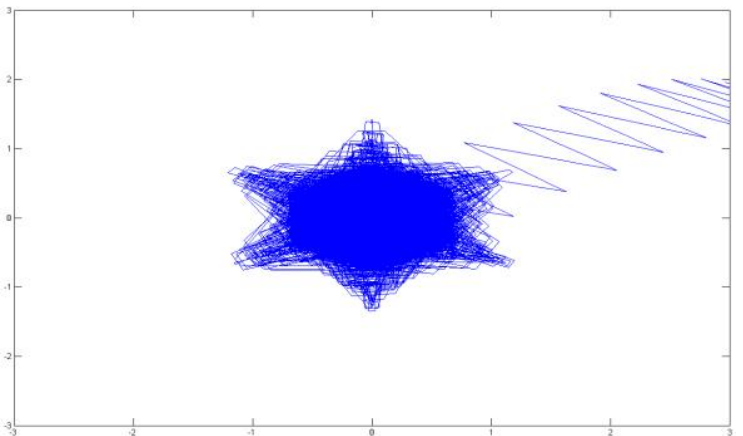

Fig. 15 The current error movement in $\alpha-\beta$ plane by delta modulator

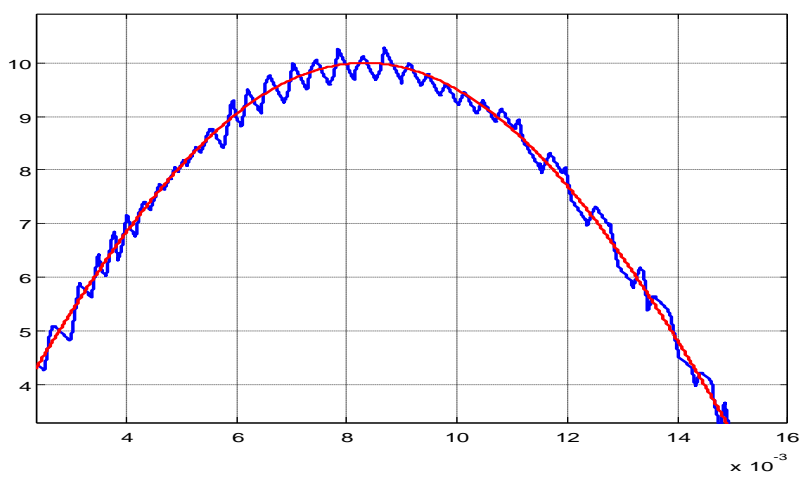

Fig.16 Control action by general current controllers

Table: 3 THD level of different load condition with delta and modified ramp type current controllers.

\begin{tabular}{|c|c|c|}
\hline Load Parameters & $\begin{array}{c}\text { THD level of load } \\
\text { current by } \\
\text { Delta Modulator }\end{array}$ & $\begin{array}{c}\text { THD level of load } \\
\text { current by } \\
\text { Modified Ramp } \\
\text { type controller }\end{array}$ \\
\hline $\mathrm{R}=30 \mathrm{ohm}, \mathrm{L}=5 \mathrm{mH}$ & $4.69 \%$ & $4.10 \%$ \\
\hline $\mathrm{R}=30 \mathrm{ohm}, \mathrm{L}=4 \mathrm{mH}$ & $4.83 \%$ & $4.20 \%$ \\
\hline $\mathrm{R}=20 \mathrm{ohm}, \mathrm{L}=3 \mathrm{mH}$ & $5.35 \%$ & $4.50 \%$ \\
\hline $\mathrm{R}=20 \mathrm{ohm}, \mathrm{L}=2.5 \mathrm{mH}$ & $5.70 \%$ & $4.64 \%$ \\
\hline
\end{tabular}

\section{CONCLUSION}

This paper presented the comparative study between a novel delta modulator and modified ramp type current controller for current controlled voltage source inverters. Both the current controllers provide good dynamic response. But modified ramp type current controller produces more current ripple and less THD in the load current at constant switching frequency during load variations. Because modulation process limited by the carrier frequency. Novel delta modulator has proved good dynamic response, less current ripple, constant switching frequency because of the switching frequency is fixed at cutoff frequency of the integrator. This switching frequency can be varied by varying time constant of integrator or cutoff frequency, it has less parameter sensitivity and it gives more THD of load current waveforms. The experimental results have to be validated with simulation results for two current controllers in near future.

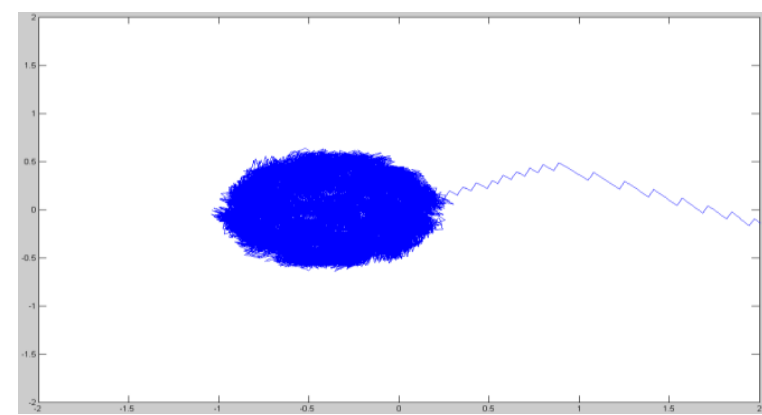

Fig. 17 The current error movement in $\alpha-\beta$ plane by modified ramp type controller.

\section{REFERENCES}

1. M.Azizur Rahman, Ali M. Osheiba. "Analysis of current controllers for voltage-source inverter" IEEE Transaction on Industrial Electronics, vol.44, no.4, Augest 1997.pp.477-485

2. M.P.Kazmierkowski, L.Malesani: "PWM current control techniques of voltage source converters- A survey" IEEE Transactions on Industrial Electronics, Vol.45, no.5, Oct.1998, pp.691-703.

3. D.M. Brod and D.W. Novotny: "current control of VSIPWM inverter", IEEE Trans. Ind. Applications., Vol. IA, My/June 1985. pp.562-570

4. L.Malesani and P.Tenti. "A Novel hysteresis control method for current-controlled voltage-source PWM inverters with constant modulation frequency", IEEE Transactions on Industrial Electronics, Vol.26, pp.321-325.1998.

5. S.Ogasawara, H.Akagi and A.Nabae: "A Novel PWM Scheme of Voltage Source Inverter based on Space Vector Theory". Proceedings of European conference on power ElectronicsApplications, EPE-89, Aachen, Oct.1989, pp.1197-1202.

6. Ajay Tripathi and P.C.Sen, "Comparative Analysis of Fixed and Sinusoidal Band Hysteresis Current Controllers for Voltage Source Inverters" IEEE Transactions on Industrial Electronics. Vol.39, Feb1992.pp.63-73.

7. P. Enjeti, P. D. Ziogas, J. F. Lindsay, and M. H. Rashid, “A Novel Current Controlled PWM Inverter for Variable Speed AC Drives", Proceedings of IEEE IAS 1986 Annul. Meeting, 1986, pp. 235-243.

8. Luigi Malesani and Paolo Thnti "A Novel Hysteresis Control Method for Current-Controlled Voltage-Source PWM Inverters with Constant Modulation Frequency", IEEE Transactions on Industrial Applications, Jan-1990, pp.88-92.

9. Simone Buso and Luigi Malesani, "Comparison of Current Control Techniques for Active Filter Applications", IEEE Transactions on Industrial Electronics, Oct-1998. Vol.45,pp.722-729

10. J.Rodriguez and C.Silva, "Predictive Current Control of a Voltage Source Inverter" Proceedings of IEEE 35th Annual Power Electronics Specialists Conference, Germany 2004.pp.2192-2196. 
11. Phoivos D.Ziogas, "The Delta Modulation Technique in Static PWM Inverters" IEEE Transactions on Industrial Applications, March/April 1981.pp.199-204.
12. T.L. Grant and T.H.Barton, "Control Strategies for PWM Drives", Proc. of Annul Conference on Industry Applications Society, Ann. Meeting.March-1980. pp.785792. 